\title{
AS FACES DA MORTE: UM ESTUDO ANTROPOLÓGICO DAS VARIADAS FORMAS DE INUMAÇÃO
}

Por Inajara Kaona Weiss ${ }^{1}$

\begin{abstract}
Resumo
O presente estudo tem por objetivo apresentar, por meio de um estudo bibliográfico, uma análise antropológica dos rituais funerários exercidos em diversas culturas e sociedades, com o intuito de ilustrar como esses elementos guiam a construção da identidade cultural das sociedades aludidas. Discorre também sobre os variados tratos com o defunto, com o objetivo de possibilitar uma análise da estrutura cultural destas sociedades. É abordada ainda, a questão da morte como um acontecimento social, a morte como um ritual de passagem, como fator da construção da identidade social, a morte como começo de uma nova forma de vida. Discorro, também sobre o poder relacionado à morte enquanto fato social.
\end{abstract}

Palavras chave: Rituais Funerários. Religião. Inumação.

\begin{abstract}
The present study aims to present, through a bibliographic study, an anthropological analysis of funerary rituals exercised in different cultures and societies, in order to illustrate how these elements guide the construction of cultural identity of the aforementioned companies. Also discusses the various dealings with the deceased, with the goal of enabling an analysis of the cultural fabric of these societies. It also addressed the issue of death as a social event, death as a rite of passage, as a factor in the construction of social identity, death as the beginning of a new life form. I discourse, also on death related to power as a social fact.
\end{abstract}

Keywords: Funeral Rites. Religion. Interment.

\section{DESENVOLVIMENTO}

Com todas as diversas transformações e mudanças históricas pelo qual a humanidade já passou, existem ao menos duas questões que permaneceram constantes e inalteradas: os seres humanos nascem e morrem. Com relação à morte, pode-se afirmar que "é um fato, um acontecimento que se repete, como simples episódio, na existência de

\footnotetext{
${ }^{1}$ Mestranda em Ciências Sociais, Unioeste, Toledo-PR.
} 
cada um de nós"' (SCHADEN, 1954, p. 153). É desta forma, um fato singular e concreto, mas que possui interpretações variadas. A morte pode ser pensada como um

[...] produto da história. Ao mesmo tempo, a história, tanto quando produto da vida dos homens em sociedade, é o resultado da morte deles. As sociedades se reproduzem porque seus membros morrem (RODRIGUES, 1893, p.115).

Deste modo a própria reprodução da civilização pode ser vista como uma maneira de responder à problemática colocada pela vida e pela morte, já que as regras organizacionais e as normas só adquirem sentido porque ocorre a morte das antigas gerações, fazendo-se assim necessária a transmissão destes regulamentos às gerações que estão por vir. A morte como acontecimento social (social, pois envolve não somente o defunto, mas toda a estrutura social e as relações que o falecido mantinha em vida) pode ser vista como um fato de ordem coletiva, pois com o falecimento de um componente desta organização social, todo o sistema no qual o indivíduo está inserido entra em crise; segundo José Carlos Rodrigues, “[...] a morte de um indivíduo não é um evento isolado, mas representam tantos eventos quantas relações o indivíduo morto mantivesse em vida..." (RODRIGUES, 1983, p. 85).

A partir do momento que o homem toma consciência de si mesmo como indivíduo, ele se vê afetado pela morte. O homem por assim dizer é o único que possui verdadeira consciência da morte, sabendo, portanto, que sua vida não é eterna, mas sim finita. Já os animais não são providos desta consciência, conforme discorre Edgar Morin:

[...] os animais, por não serem dotados de uma consciência individual. 'conhecem' a morte apenas como uma morte-agressão, uma morteperigo, uma morte-inimiga na luta pela sobrevivência. Para os animais vale o instinto: é a espécie que conhece a morte, não o indivíduo. Neste sentindo, o animal é cego para a morte, pois ele não tem consciência, não tem idéias. A cegueira animal à morte é uma cegueira à individualidade. A morte-perda-de-individualidade só os humanos conhecem (MORIN, 1997, p. 69).

Essa aquisição de consciência da própria morte está intimamente ligada à vida em sociedade organizada, não se tratando mais de uma questão de instintos como nos primórdios do pensamento humano, mas sim de um leque de variadas representações criadas por diversas culturas em torno do falecimento.

Portanto, "a consciência da morte é uma marca da humanidade" (RODRIGUES, 1983, p. 19). Com a aquisição da mesma, o homem começa um processo de 
materialização do óbito, sendo as sepulturas um exemplo disso. Elas traduzem "[...] um processo de conhecimento objetivo, trata-se da necessidade de se exprimir algo, tomando a consciência de que o corpo morto de um humano não pode ser considerado como um defunto qualquer" (RODRIGUES, 1983, p. 20). É necessário, deste modo “esconder, queimar, apressar, intervir de alguma forma, mitificar, enterrar, comer, cremar [...]", (RODRIGUES, 1983, p. 68), o corpo em óbito, sendo que nenhuma sociedade consegue permanecer ausente ou indiferente ao acontecimento da morte. A humanidade, por conseguinte, ao longo do processo histórico, constitui um conjunto de crenças e de representações frente ao fenômeno do falecimento. São esses comportamentos culturais que vão nortear as atitudes dos membros das sociedades diante deste evento, sendo que a maneira como uma determinada sociedade se coloca perante a morte exerce uma função decisiva na construção e manutenção de sua própria identidade coletiva.

Entre os rituais funerários, o ato de sepultar os mortos, ou seja, a inumação é uma das práticas mais difundidas e exercidas entre as culturas, onde a mesma, por conseguinte não pode ser vista meramente como um processo de higienização ou de afastar os vivos de um possível foco de doenças - pois como será abortado adiante - existem sociedades em que o indivíduo pode ser enterrado antes mesmo de o óbito físico ocorrer, ou no caso de outras culturas que convivem com o defunto por dias, até que este esteja com um grau de putrefação alto - um exemplo desta prática pode ser observado entre os habitantes da cidade de Zanaga, localizada no Congo - onde os restos mortais [...] são conservados até seis meses, improvisando-se sobre o leito mortuário um canal que recolhe os líquidos cadavéricos e os conduz aos lugares exteriores (ZIEGLER apud RODRIGUES, 1983, p. 20). Já entre os Toradja do Sul, da Indonésia, o corpo do defunto "antes de sua inumação definitiva, [...] é objeto de um culto extremamente complexo, que às vezes pode durar algumas dezenas de anos - porque é necessário tempo para atingir o domínio dos mortos, para nele ser aceito, para se integrar à sociedade do além"' (RODRIGUES, 1983, p. 45).

A técnica de inumação pode ocorrer de formas variadas, não somente do modo ocidental, no qual conhecemos, onde o cadáver é posto em posição horizontal, com as mãos em posição de oração dentro de um caixão, e o corpo, na maioria das vezes, é coberto por flores, e enterrado em um lugar destinado - esses locais hoje são os cemitérios - mas também o defunto pode ser inumado em vasos, cestos, enterrado com pedras amontoadas em sua cabeça, ou sepultados diretamente ao solo. Sendo que a posição que se coloca o morto no ato do enterro também pode variar bastante, por exemplo, 
[...] de barriga pra baixo (como as mulheres adulteras dos últimos séculos europeus); em pé como alguns militares, cabeça separada do corpo em um sentido invertido, como no caso dos condenados a guilhotina, em posição fetal, como nas urnas pré-colombianas, sentados, como nos cemitérios muçulmanos na Síria e entre alguns monges na região de Nantes, [...] deitados de costas, com a cabeça virada em direção a Meca (RODRIGUES, 1983, p. 53).

Em todas as sociedades, portanto, algo deve ser feito com relação ao corpo em óbito, e é neste sentido que os rituais funerários vêm de encontro com a construção de um sistema de crenças e práticas específicas de cada cultura que contribuem para dar sentido à transformação que a morte provoca, tanto no indivíduo quanto na esfera social.

É neste sentido que, a partir da aquisição de consciência da própria morte como mencionado anteriormente, o ser humano começa a sistematizar o óbito, sendo que em cada cultura a morte alude a um ritual funerário específico. Essas práticas estão calcadas dentro de um campo semântico onde cada cultura insere a morte em um sistema de classificação a fim de compreendê-la e de lhe atribuir sentido. Cada cultura também atribui singular significado às várias mortes-acontecimentos possíveis. No Brasil

[...] uma pessoa pode morrer de morte morrida, morte de velhice, de morte matada, de morte violenta... Cada uma delas provocando nos sobreviventes uma particular relação emocional. Morrer de 'morte morrida', significa que não é necessário procurar um culpado e que o indivíduo chegou ao termo de sua existência biológica por razões ligadas ao próprio funcionamento do organismo. Morrer de 'velhice' [...] é a morte do ancião, que lentamente se aproxima de seu fim. Já morrer de 'morte matada' [...] inclui todos dos os eventos de morte para os quais se poderiam apontar um responsável: morte por acidente, assassinato,... (RODRIGUES, 1983, p. 26).

Sendo assim, o óbito pode ocorrer por vários fatores, seja acidental ou decorrente de uma enfermidade, de suicídio, de catástrofes da natureza, ou de morte insólita, por feitiçaria, ou também, por influência do coletivo como discorre Marcel Mauss:

[...] num número muito grande de sociedades, uma obsessão pela ideia de morte, de origem puramente social, sem nenhuma mistura de fatores individuais, era capaz de tamanhas devastações mentais e físicas, na consciência e no corpo do indivíduo, que ela provoca sua morte em pouco tempo, sem lesão aparente ou conhecida (MAUSS, 2003, p. 347).

Sendo a morte, portanto, um acontecimento que remete ao grupo social, as ideias que são elaboradas pelo coletivo se reproduzem no indivíduo. Mauss (2003) utiliza como 
base para este estudo os rituais funerários de civilizações australianas e a dos Maori, da Nova Zelândia. Ao longo do texto o autor relata algumas mortes ocorridas devido à influência do coletivo, onde, por exemplo,

No distrito de Kennedy, em 1865, no estudo dos Eden, uma velha empregada irlandesa censura a uma empregada negra seu egoísmo, dizendo-lhe morrerás logo por seres tão cruel. A mulher ficou parada por um minuto, suas mãos caíram, empalideceu e desesperada, sob o efeito das palavras, consumiu-se e em menos de um mês, morreu (MAUSS, 2003, p. 354).

A força social sobre a natureza psíquica e fisiológica do indivíduo é tão grande, que mesmo sem estar de fato doente ou com alguma lesão aparente o indivíduo vem a falecer, por razões puramente coletivas. A morte também pode ser pensada como um rito de passagem, pois o óbito "é a passagem de uma forma de vida social a uma outra; ela não é o fim da vida, mas iniciação a uma nova"' (RODRIGUES, 1983, p. 46).

Julio Cezar Melatti também faz uma abordagem sobre os ritos funerários que articulam com os rituais de passagem em seu livro "Índios do Brasil". Sobre a questão, o autor afirma que

[...] os ritos de passagem são cerimônias que são realizadas para que um indivíduo ou um grupo atravesse de uma situação a outra, por exemplo, quando uma pessoa vem a falecer ela passa em um primeiro momento por uma fase de separação onde deixa de estar no mundo dos vivos, e em seguida a transição para o mundo dos mortos acontece, e por fim o cadáver é incorporado em sua situação final (MELATTI, 2007).

Como de forma geral a crença da existência da alma está presente em várias culturas, após o falecimento a alma que está incorporada no corpo em vida é liberada para seguir para outro mundo. É neste sentido que os rituais funerários estão articulados com as cerimônias de passagem, pois com a morte física, a morte da alma não ocorre, e a mesma se evade para uma outra espécie de vida. Nesta perspectiva a morte é a passagem para uma nova forma de vida e de existência.

O óbito também “[...] não se limita a por fim a existência corporal. Ela destrói ao mesmo tempo o ser social investido sobre a individualidade física, ao qual a consciência coletiva atribuía uma maior ou menor grau de dignidade' (HERTZ apud RODRIGUES, 1983, p. 20). Ou seja, o falecimento de um indivíduo, neste sentido, remete não somente à morte física mais também a todo o conjunto ao qual essa pessoa estava interligada, sendo portanto, à morte da interação do sujeito com a sociedade. O indivíduo, contudo, 
somente terá uma morte completa quando for esquecido definitivamente pela sociedade, ou quando todos os seus descendentes também falecerem. Assim, a morte física não basta para que a morte ocorra na memória das pessoas, o falecido continuará vivendo nas lembranças coletivas. Somente com esse esquecimento é que de fato o falecido morre, “contudo [...] certos mortos privilegiados permanecem nomeados e identificados, às vezes são transformados em gênios, santificados ou divinizados" (RODRIGUES, 1983, p. 102).

Se o óbito do indivíduo alude à morte da interação social e a passagem para outra forma de vida, uma pergunta cabe ser feita: para onde vão as pessoas depois da ocorrência do falecimento? Já que as práticas funerárias são realizadas com o objetivo de desagregar o morto de um domínio e introduzi-lo a outro, sendo que a inumação e outras práticas exercidas com o corpo morto são meios de assegurar que o falecido parta deste mundo e caminhe na direção correta do seu lugar estabelecido. Portando qual é o local destinado aos mortos?

Para essa pergunta existem várias respostas distintas, algumas culturas acreditam que ao morrer o defunto vai para um novo mundo, uma réplica do mundo dos vivos só que sem infortúnios onde todos são plenamente felizes.

[...] entre os Dayak a sociedade dos mortos também se assemelha á dos vivos: a aldeia do além é vista como qualquer aldeia terrestre com suas divisões, indo o morto para um setor 'elegante' ou 'miserável' de acordo com o número de sacrifícios oferecidos pelos sobreviventes. Os Cocopa, da Califórnia, imaginam igualmente a mesma vida terrestre, embora sobre uma terra mais fértil (THOMAS apud RODRIGUES, 1983, p. 36).

Na tradição judaico-cristã, também há a crença de que, ao morrer, vamos para um lugar parecido com a terra - chamado de céu - mas sem violência, fome, sofrimento e, principalmente, sem morte, onde os indivíduos que alcançarem esse paraíso irão desfrutar da felicidade completa e eterna. Para adentrar neste local o falecido terá que fazer por merecer através de boas ações realizadas em vida, e se o defunto tiver sua conduta desviada - por cometer pecados - o lugar destinado a ele será o inferno. O inferno é o oposto do céu, sendo neste local que se encontra o temido Diabo, uma entidade destinada a fazer o mal e persuadir as pessoas em vida a cometerem pecados. É por essa razão que há um imenso temor dos indivíduos de acabar sua eternidade neste lugar, pois é visto como um lugar de sofrimento e de muita dor. No céu, por sua vez, encontra-se o adorado Deus, um ser benevolente que preza pelo amor e pelas boas ações. A tradição islâmica, 
nesse sentido, se aproxima da judaico-cristã, pois eles também acreditam que a vida no além dependerá do comportamento que o indivíduo levou na terra.

Já no caso dos Bella-Coola, da Colômbia, o mundo dos mortos é totalmente o oposto ao dos vivos, no sentido de que as coisas no outro mundo adquirem um significado inverso daquele atribuído em vida. Por exemplo: as comidas que em vida possuem gosto amargo são saborosas no mundo dos mortos. Essa mesma visão pode ser observada entre os Brou que vivem no Camboja. Para eles, "[...] o mundo da morte é o de uma "vida invertida', onde o defunto se serve da mão esquerda, utiliza marmitas perfuradas, ferramentas sem cabo e sem corte, etc. Uma vida invertida, mas também vida melhor" (TRUBETZKOY apud RODRIGUES, 1983, p.37).

Para a Igreja Católica, com a morte ocorre a separação da alma do corpo, ao passo que a alma do cristão vai ao encontro de Deus, ficando a espera de ser novamente unida ao corpo que ressuscitara, sendo que Deus, em sua onipotência, restituirá definitivamente a vida dos restos mortais, unindo-os as respectivas almas.

A morte, por conseguinte, nestas diferentes mitologias, não é o fim da vida, mais sim a passagem para uma nova forma de existência, e esse processo de transição não ocorre repentinamente, sendo necessária a realização das práticas funerárias, afim de que esse percurso ocorra. Por isso são várias as sociedades que exerceram técnicas como a mumificação (comum no antigo Egito $^{2}$ ), visando à preservação do corpo do morto, e outros que enterram os entes com comida, com suas armas, com seus pertences, afim de que o falecido tenha as suas necessidades momentâneas supridas no novo mundo. Essa crença pode ser observada no relato descrito abaixo

No estado de Chiuaua, no norte do México, o morto é enterrado com milho, feijão, seus arcos, suas flechas e um pote de tesvino (espécie de cerveja de milho), porque as pessoas acreditam ser melhor atender logo as necessidades do morto que proporcionar-lhe ocasião de retornar para satisfazê-las (RODRIGUES, 1983, p. 30).

O medo de que os mortos aspirem permanecer com os familiares vivos também é uma preocupação presente em algumas sociedades, pois com o fim da realização dos

\footnotetext{
2 “Os egípcios acreditavam que o ser humano era formado por $K a$ (o corpo) e por Rá (a alma). Para eles, no momento da morte, a alma se desligava do corpo, mas ela podia continuar a viver no reino de Osíris ou de Amon-Rá. Isso seria possível somente se fosse conservado o corpo que devia sustentá-la. Daí vinha à importância de embalsamar ou mumificar o corpo para impedir que o mesmo se descompusesse. Para assegurar a sobrevivência da alma, caso a múmia fosse destruída, colocava-se no túmulo estatuetas do morto" (HARRIS L. 2004).
} 
ritos funerários espera-se que o falecido esteja devidamente conduzido para o lado do além, e algumas precauções neste âmbito são tomadas para que se garanta que o defunto tenha realmente partido. Neste sentido, segundo Louis Vicent Thomas,

[...] numerosos esqueletos antigos foram descobertos com indícios de terem sido amarrados. Em Queensland, quebravam-se os ossos do morto, prendiam-se os joelhos perto do queixo e enchia-se o estomago de pedras. O mesmo sentimento, provavelmente, levou a colocar grandes blocos de pedras sobre o peito do defunto, a fechar hermeticamente as sepulturas, a fechar com pregos as urnas e os caixões. Por toda parte; é necessário disciplinar a ingerência dos mortos na vida dos vivos (THOMAS apud RODRIGUES, 1983, p. 33).

Preza-se, portanto, que haja a separação dos mortos do mundo dos vivos. As práticas antropofágicas exercidas na cultura Guayaki, do Paraguai, podem exemplificar bem esse processo, com a ingestão dos restos mortais - seja dos inimigos de guerra que possuam alguma virtude ou de algum membro da tribo - ocorre o afastamento do defunto do mundo dos vivos e sua condução ao mundo do além. Essa prática é realizada com o intuito de evitar que a alma do falecido aspire retornar a tribo, pois se ela retornar vai tentar levar consigo as almas dos vivos e para que isso não corra os Guayaki, comem o morto, pois “[...] ao comer o corpo, separa-se o cadáver da alma, dificultando-se assim a conjunção entre o corpo de um vivo e a alma de um morto: se a alma resolver invadir um corpo vivo, o que é que ela encontrará? - seu antigo corpo despedaçado e consumido" (RODRIGUES, 1983, p. 61). A alma do morto ao depara-se com seu corpo mastigado, no interior de um outro corpo vivo, não consegue retornar ao mundo dos não mortos, sendo obrigado a partir para seu lugar devido. Desta forma “[...] a aproximação de um corpo vivo com um corpo morto significa o distanciamento entre vivos e mortos, pois, com a impossibilitada de retornar a este mundo, a alma do morto decide partir para o outro', (RODRIGUES, 1983, p. 61).

No ritual antropofágico Guayaki, não são todos da tribo que podem participar desta cerimônia, como também existe a repartição da carne do falecido entre os membros da tribo. Após cortar o corpo em pedaços, “[...] a cabeça como a dos animais, é reservada aos velhos homens e mulheres, e proibida aos caçadores jovens [...]. Quanto ao pênis ele é sempre destinado às mulheres e, entre elas, àquelas que estiverem grávidas" (CLASTRES apud RODRIGUES, 1983, p. 60). Já após a quebra dos ossos e a extração da medula, é de competência das mulheres mais velhas consumirem essa parte. 
Essa separação - dos vivos e dos mortos - não impossibilita o morto de se "manifestar" para os vivos, sendo que no ato de canibalismo pode-se notar que o morto continua em comunicação com a tribo já que seu corpo permanece entre os indivíduos vivos. Em determinadas religiões, como o espiritismo, essa manifestação pode ser notada através da prática da psicografia onde uma pessoa que tenha mediunidade, ou seja, tem certa capacidade humana que permite a comunicação entre os vivos e os mortos, conseguindo por meio do seu corpo exteriorizar o desejo e a fala do falecido. Isso ocorre porque a alma do morto incorpora no corpo do vivo, podendo esse então falar pelo defunto e expressar a sua vontade. E “[...] no candomblé da Bahia a função da casa dos mortosque-voltam, no terreiro de Egun, é garantir uma comunicação ininterrupta entre os vivos e os mortos, mas de um modo regrado a fim de possibilitar o 'livre fluxo do saber social dos ancestrais", (FRANZEN apud RODRIGUES, 1983, p.33).

A morte, como já mencionado, é um acontecimento coletivo e social, que por sua vez exerce sobre o indivíduo o que Mauss (1981) chamou de "expressão obrigatória dos sentimentos": "Não são somente os choros, mas todos os tipos de expressões orais dos sentimentos que são essencialmente, não fenômenos exclusivamente psicológicos, ou fisiológicos, mas fenômenos sociais, marcados eminentemente pelo signo da nãoespontaneidade" (MAUSS, 1981, p. 325). Ou seja, o sentimento que se manifesta e que são expressos não é determinado pelo indivíduo, mas sim por uma imposição social.

Desta forma, "os sentimentos são ritualizados e socialmente propostos, observemos que tristeza, indiferença e alegria não são necessariamente sentimentos reais, experimentados pelo indivíduo, mas, antes, comportamentos convencionais" (RODRIGUES, 1983, p. 43). Um exemplo disso são as chamadas carpideiras, que são pessoas contratadas para chorar e exteriorizar o sentimento de dor nos funerais, com a intenção de demonstrar para a sociedade que o falecido era uma pessoa querida e amada. Desta forma a intensidade da lamúria representa o nível de apreço que as pessoas tinham ao falecido.

Ainda hoje em alguns funerais do Oriente Médio "se contratam carpideiras rituais para que elas aumentem a intensidade dos lamentos, e as dimensões da tristeza socialmente obrigatória: elas se arrancam os cabelos, espalham cinzas, rasgam suas roupas, laceram a si mesmas com as unhas, num ritual que talvez provoque mais emoções do que exprima', (RODRIGUES, 1983, p. 44).

Há várias maneiras de se expressar o sentimento pela morte de alguém, e cada uma delas é determinada por eventos específicos. Entre os Bororo, do Mato Grosso, 
segundo Rodrigues (1983), se o defunto exercia uma determinada posição social, como uma pessoa de meia idade, por exemplo, a demonstração de lástima é maior do que se o morto fosse um recém-nascido, pois o indivíduo adulto já possuía relações sociais bem definidas tendo exercido deste modo uma maior contribuição social, ao contrário da criança. Portanto,

[...] se chora, se geme, não simplesmente para expressar uma dor individual; é para cumprir um dever que a sociedade circundante não deixa de recorda-lhe quando chega o caso. Com efeito, e em suma, quando choramos pela morte de uma pessoa e não choramos pela morte de outra, estamos, no primeiro caso, cumprindo uma obrigação que diz respeito à relação entre o nosso status e o status da pessoa que morreu; e dispensados dessa obrigação no segundo caso (RODRIGUES, 1983, p. 44).

Para algumas religiões, como o Budismo, a morte e o nascimento estão no mesmo patamar, sendo que após a morte de um indivíduo o mesmo será condicionado à reencarnação para que ocorra o aperfeiçoamento de sua alma. Cada estadia na terra é considerada um aprendizado onde antigos erros e desavenças cometidas em outras vidas possam ser resolvidos. Desta forma o defunto volta à terra em outro corpo quantas vezes forem necessárias para atingir o chamado Nirvana que pode ser visto como uma

[...] libertação definitiva dessas existências sucessivas [...]. O Nirvana é a vida indeterminada, mas total, é êxtase, quer dizer, amor e plenitude, mas também é vazio e nada. O Nirvana é a extinção da engrenagem de renascimentos e mortes, é o fim da impermanência, é a eterna felicidade (BUDA apud RODRIGUES, 1983, p. 37).

Outra crença que envolve nascimento, morte e reencarnação pode ser observada no Hinduísmo, onde a reencarnação depende dos méritos que o falecido obteve em vida, por exemplo, se um indivíduo durante a sua existência na terra praticou o mal ele reencarnará em animais medíocres como os insetos. Essa visão de que a vida no além, ou a reencarnação da alma, dependerá de seu comportamento na terra está ligada não somente à religião, mas a um certo poder social ou controle que a sociedade tenta exercer sobre o indivíduo. Em nossa cultura ocidental, por exemplo, as maiorias das religiões pregam aos fiéis que tenham um comportamento adequado, dentro das regras, para que posterior a sua morte, sua alma vá para um lugar melhor, ou seja, o céu. Caso o indivíduo não seguir a conduta correta, sua alma acabará no inferno. 
Neste sentido, pode-se dizer que a morte exerce poder sobre as pessoas. Segundo José Carlos Rodrigues, o poder que a morte possui pode ser chamado de mana.

[...], ou seja, uma capacidade geral de produzir efeitos ao nível da sociedade e de seus sistemas simbólicos. E é por causa deste mana, que ninguém permanece perto de um cadáver sem que a fisionomia ateste que é precisamente um cadáver o que se está vendo.Na nossa cultura, por exemplo, em que as pessoas não estão habituadas à visão de cadáveres, certas reações são típicas: as pessoas ousam olhar rapidamente para o cadáver e afastam os olhos imediatamente, como se quisessem separar do olhar algo que não querem ver (RODRIGUES 1983, p. 99).

Em algumas culturas o mana da morte é visto como uma preciosidade, e uma das formas do indivíduo conseguir se apropriar dele é guardando uma parte do falecido consigo, obtendo assim o poder de intervir entre os vivos e os mortos. Outra maneira de adquirir o mana da morte consiste em atar - peito contra peito e boca contra boca - o indivíduo a um cadáver e em os levar, ambos, para o fundo de um fosso, que se cobre de ramagens, onde permanecem por três dias', (SUDNOW apud RODRIGUES, 1983, p. 100).

Já entre os Krahô, que vivem no nordeste do estado de Tocantins, o mana da morte é algo muito perigoso, pois pode matar o indivíduo que entrar em contato com ele. Nesta cultura após a morte, ocorre a “[...] lavagem do corpo, o corte de cabelo. A lavagem pode ser feita dentro de casa, perto da porta, ou na frente desta. Como a água usada para tal fim torna-se perigosa, costuma-se levar a areia molhada para longe e espalhar terra nova no local” (CARNEIRO DA CUNHA, 1978, p. 29). A água usada para banhar o morto, conforme o relato se torna perigosa, impura e se por ventura algum animal beber desta água, o mesmo morrerá devido ao mana ruim do morto, que pode contaminar outras pessoas e até mesmo animais.

Em outros casos a apropriação do poder da morte se dá através do controle social, que por meio de práticas de coerção psicológica e física apodera-se da vida e morte dos homens. Por exemplo, desde a Idade Média quando o Estado e a Igreja utilizavam como meio de punição a execução, que ficava a cargo dos carrascos, essa tentativa de aquisição do poder da morte pode ser observada, pois essas instituições exercem o poder de matar a quem não cumprir as regras estabelecidas ${ }^{3}$.

\footnotetext{
${ }^{3} \mathrm{Na}$ conferência intitulada, “A morte como quase acontecimento" (2009) Eduardo Viveiros de Castro, afirma que a morte na cultura ocidental, no período da Idade Média, era um acontecimento de ordem pública, onde os condenados eram mortos pelas mãos dos carrascos em meio ao povo, que prontamente
} 
Ainda nos dias atuais existem Estados que autorizam a utilização da pena de morte como sentença, sendo que se evita ao máximo que o prisioneiro que espera o cumprimento da pena cometa o suicídio, pois esse ato expressa em um primeiro momento o desafio do poder imposto e em outro a liberdade que o ser humano possui diante da sua própria vida, o chamado livre arbítrio. A Igreja Católica também se encaixa neste exemplo, sendo que a mesma prega que a alma do indivíduo que comete o suicídio vai direto para o inferno, coagindo, desta forma, o indivíduo para que o mesmo não cometa esse ato.

O suicídio perante o poder pode ser visto como uma estratégia (dramática, é verdade). Como mencionado anteriormente, se um condenado à morte está confinado esperando a execução, o suicídio é para ele uma libertação, passando por cima do poder social que determinou que ele ficasse nesta situação até o dia de sua execução. É neste sentido que

[...] em Roma, o suicídio era um privilégio dos membros das elites, que poderiam beneficiar-se dele e preservar algo de sua dignidade. Enquanto isso, os escravos $\mathrm{e}$ as pessoas do povo deveriam necessariamente perecer nas mãos do carrasco. Entre nós, este 'privilégio' foi dado a alguns militares, que foram autorizados a comandar seus próprios fuzilamentos (RODRIGUES, 1983, p. 108).

Se em nossa sociedade o suicídio é visto como um ato que acarreta aos parentes um sentimento de vergonha, em outras ele é visto como algo digno. É o caso da cultura dos esquimós, onde "os velhos, que pesavam sobre a economia do grupo, caso se suicidassem teriam um lugar especial e favorável na vida pós-morte, pois abriram mão de sua vida para o bem da comunidade" (RODRIGUES, 1983, p. 109).

Em virtude dos fatos e relatos mencionados acerca dos rituais funerários e as práticas pós-morte expostas até aqui, é possível observar que “[...] todas as culturas, todas as sociedades estiveram preocupadas com mortes presentes e passadas, com cadáveres e antepassados" (RODRIGUES 1983. p. 287). E de todas as sociedades aludidas, apesar do

assistia as execuções. Segundo Castro no decorrer da história a sociedade modifica a forma de ver o óbito, na sociedade ocidental atual, a morte é vista como uma pornografia, que deve ser escondida e ocultada, tornando-se um evento de ordem particular.

Castro também aborta a questão do poder da morte, afirmando que o Estado possui um grande interesse na morte de seus cidadãos, pois como essa instituição pode exercer o monopólio da violência legítima, ou seja, tem a permissão de matar legitimamente, ela usa deste artifício para coagir e manipular os indivíduos, a seguir as regras estabelecidas pela sociedade. 
trato com o defunto divergir entre elas, o que permanece constante é que com a morte do indivíduo ocorre também à destruição do ser social, ou seja, "“...] a morte não se satisfaz em destruir o que chamamos organismo, mas inicia também um processo de dissolução do homem social, e isso em vários estágios de seu ciclo de vida" (CARNEIRO DA CUNHA, 1978, p. 02).

Por conseguinte, como foi destacado anteriormente cada sociedade possui um conjunto de crenças e representações particulares referente ao óbito, formulando desta maneira comportamentos sociais específicos que respondem e dão sentido à lacuna deixada pelo falecimento de um ente querido. Por isso a importância destes rituais, pois com a realização dos mesmos as transformações que a morte provoca nos indivíduos que permanecem neste mundo e na esfera social são melhores compreendidos. Sendo assim, os rituais funerários amparam e dão esperança, aos que vivem, de que a morte não é o fim de tudo e sim um começo de um novo formato de vida.

\section{REFERÊNCIAS BIBLIOGRAFICAS}

CUNHA, M.C.D. 1978. Os mortos e os outros: uma análise do sistema funerário e da noção de pessoa entre os índios Krahó. São Paulo: HUCITEC,

GEERTZ, C. Ethos.1978. Visão de mundo e a análise de símbolos sagrados. In: A interpretação das culturas. Rio de Janeiro: Zahar.

HARRIS L. E. 2004. Magia e divinações do antigo Egito. Rio de Janeiro: Ed Nova Era. MAUSS, M.1981, A expressão obrigatória dos sentimentos (rituais orais funerários). In: . Ensaios de sociologia. São Paulo: Perspectiva. p. 325-335 2003. Efeito físico no indivíduo da idéia de morte sugerida pela coletividade (Austrália e Nova Zelândia) In: . Sociologia e antropologia. São Paulo: Cosac \& Naify. p. 345-365

MELATTI .J.C.1993. Índios do Brasil. São Paulo: Hucitec; Brasília: Edunb.

MORIN, E.1997. O Homem e a morte. Rio de Janeiro: Ed. Imago.

RODRIGUES, J.C.1983. Tabu da morte. Rio de Janeiro: Achiamé, 1983.

SCHADEN, Egon. Aspectos Fundamentais da Cultura Guarani. São Paulo: EPU; EDUSP, 1954. 
